into the lake in its lower part when it is covered with ice, must supply water at $32^{\circ} \mathrm{F}$; for even if it were at a bigher temperature while forming part of the stream, it would, by impinging on the edge of the lake ice, be cooled down before being able to mix with its waters. It would thus enter the lake at $32^{\circ}$ and would spread itself out immediately under the ice, and its effect on the temperature of the water would be similar to that produced by the thickening of the ice and conduction from it.

The excess of water which falls into the upper and open part of the lake must also find its way under the ice to the outlet. In order to estimate its effect, we must consider the conditions obtaining at the terminal edge of the ice stretching across the lake. We have already discussed what takes place when the first ice fringe forms at the sides of a lake, and we may look on the ice covering the lower and shallower part of the lake, as the fringe on that side of the upper and deeper basin. The same convection currents which we have described will take place here, giving us a surface current from the ice, and an under current towards the ice, now the water in finding its way under the ice to the outlet, will take the easiest way possible, and as it will find itself retarded or opposed at the surface near the ice edge, and assisted near the bottom by the convection circulation, its supply will be delivered by preference as an under and therefore comparatively warm current. Off the edge of the ice I found the water at $8 \frac{1}{2}$ fathoms $37^{\circ} 2^{\circ}$, and in $17 \frac{1}{2}$ fathoms $374^{\circ} \mathrm{F}$. In accordance with the same principle of greatest easiness, this water would penetrate into the frozen basin by the deepest existing channel. The lower or frozen basin is separated from the upper and open one by a remarkable chain of islands separated from each other by channels everywhere less than there, and indeed hardly anywere more than two fathoms deep. The two channels however next the main land are each five fathoms deep, and it is through them that the bulk of the water finds its way. This was shown in a very singular way by the existence of a space of open water stretching from the main land to the nearest island over the shallowest part of the channel on the Dumbartonshire shore, there being thick strong ice over the deep water on both sides. In its passage over the ridge which rises very steeply, the warm water is thrown up near the surface and its supply is sufficient not only to preserve this space of open water, but also to raise the temperature of all the water of a depth greater than five fathoms in the lower basin.

In the case then of a lake only partially frozen, the temperature of the water under the ice is lowered by the drainage entering where it is frozen and is raised by the water supplied from the open part provided the channels connecting the two parts are not too shallow.

In Linlithgow Loch which was entirely frozen over, the very great rise of temperature near the bottom was caused by the immense quantity of filth contained in its water and in the mud at the bottom.

J. Y. BUCHANAN

\section{ON THE BURSTING OF THE GUN ON BOARD} THE THUNDERER ${ }^{1}$

I $N$ the interval which elapsed between the bursting of 1 the gun and the report of the Committee much thought and some trouble has been expended in divining the possible causes which might, under one set of circumstances or another, have led to such a result. It now appears, however, that, different as have been the various suggestions, they all resembled each other in one particular, namely, that they were all wrong.

It is to be hoped, however, that all the ingenuity that has been expended will not have been thrown away, and that some improvement may result from the pointing out

${ }^{x}$ Read before the Lit. and Phil. Society of Manchester on February 18, by Prof. Osborne Reynolds, F.R.S., Professor of Engineering, Owens College, Manchester. of such numerous defects. That in some respects, such as the increasing twist and the sudden steps or shoulders on the outside of the gun, the present system is defective, is shown quite apart from the recent accident; and although it now appears that the moving forward of the shot as the rammer was withdrawn had probably nothing to do with this accident, it cannot be considered satisfactory that this moving forward should be so much the rule as it is shown to have been in the experiments recently undertaken.

Although at first sight it may appear that the fact of the gun having been loaded with two charges of powder and two shot is amply sufficient to explain the bursting, it may not be useless to examine somewhat closely into what would result under such circumstances. The bursting of a 38-ton wrought-iron gun is an experiment of which we should make the most as we cannot expect to have it often repeated.

From the first accounts of the accident it appeared as though the gun had simply broken in two, like a carrot, at the first step, and that the front half had gone into the sea. Such a failure would not have implied an excess of pressure. It might have been caused by a great end strain such as would have resulted had the shot jammed when in full career and carried away the fore part of the gun, or it might have resulted from the gradual weakening of the section of the gun at the shoulder owing to the different degrees of expansion immediately before and immediately behind. One or other of these causes appeared to afford the most probable explanation of the phenomena as described in the early accounts. In various subsequent reports, however, it was stated that fragments of the fore part of the gun were blown about in all directions. So that the gun, instead of having simply broker in two, must have burst like a shell in front of the first shoulder. This fact placed the phenomena in an altogether different light. The explosive bursting of the zone of the gun into fragments implied an enormous excess of pressure at this point of the gun.

In order to cause the tube of the gun to burst longitudinally at all would require several times the normal pressure, and the breaking up of the wrought-iron tube into fragments would show that the force was largely in excess of what was necessary to burst it.

After seeing these reports it appeared certain that the gun had been subjected, at the point of rupture, to a pressure enormously excessive, and the question became whence could such a pressure have arisen? To me it appeared that nothing short of such an action as might, with a detonating fuse, result from the explosion of guncotton or dynamite would explain the breaking of the gun into fragments. Had the shot become jammed the pressure might have been raised sufficiently to burst the gun, but with pebble powder even this seemed doubtful, and such an action seemed altogether inadequate to explain the breaking of the gun into fragments. It appeared, therefore, that there was but one conclusion to be drawn--there had been something abnormal in the loading. Had the gun been loaded with small grained powder, gun-cotton, or dynamite, instead of pebble powder, such a result might have been produced; but then, the gun would, if it had burst, have burst at the breach unless the shot had slipped forward, and that there should have been two accidents appeared highly improbable. Besides, it was necessary to consider what sort of a mistake was most likely to have occurred; and the only possible mistake that could have been made on the spot appeared to be that of double loading.

The fact that if two complete charges were put into the gun, the powder of the second charge would be directly beneath the point of rupture appeared in favour of this. the easiest mistake. But would, supposing the powder to have been pebble powder, the pressure from the two charges have been sufficient to cause the result? At first 
it seemed to me that even supposing that the second charge had been ignited by the first, which was doubtful, this would not explain the suddenness or magnitude of the pressure. But on further consideration it appeared certain that the second charge would not be ignited by the fire from the first; and it then became clear that in this very fact we should have an amply sufficient explanation of the excessive pressure.

My object in writing this paper is to point out the probability of this explanati on, and so, if possible, to induce the authorities to test it. It occurred to me several days before the report of the Committee appeared, and in spite of the improbability of such a mistake as double loading, I could not shake off the conviction that it afforded the true explanation. As I have pointed out, the blowing into fragments of a wrought-iron tube implied an explosive action such as might result from guncotton or dynamite, but which could not be produce 1 by the slow burning of pebble powder. The point to be explained, then, is how the second charge could be brought into such a condition that it would explode like gun-cotton. To understand this, it must be remembered that in the usual way the grains of gunpowder burn from their outside only, so that the thicker the grains the longer will be the time occupied in burning, and for the same weight of powder the slower will the gas be given off. The reason why gun-cotton is so much more destructive than gunpowder is not that it gives off more gas weight for weight, but that when ignited by a flash it burns so much quicker. If, therefore, by any means the whole mass of gunpowder could be heated up to the firing point at the same instant, so that the grains fired simultaneously inside as well as out, the action of the powder would be as quick or quicker than the gun-cotton. And, still further, if besides being heated the powder was compressed into a fraction of the space it usually occupies, the gases so confined would be capable of a still greater pressure.

Now if the after cartridge were fired and the forward cartridge were not ignited by the flash, and considering the length and fit of the shot, it could hardly have been so ignited, then the after shot would be driven forward closing on to the forward shot and compressing the powder between until the pressure on the forward shot was at least half as great as the pressure of the gases behind the after shot, which would be between ten and twenty tons on the square inch. Thus the powder would be subjected to a squeeze between the two shot such as would result from a blow. It would be compressed to a fraction of its former volume. The cubes would be crushed into a cake and the work of compression would be sufficient to heat the powder far beyond its point of ignition. Thus the entire mass of powder would be simultaneously ignited in a highly compressed and heated state. The force of in an explosion would be practically unlimited and would be located at the very point at which the gun burst. Hence in such an action we have ample cause for the effect produced.

But it will be asked why does not the same thing happen when a rifle is doubly loaded? It is said that in that case the second cartridge is generally blown out before it ignites, and this may be so, for in the rifle the intensity of the pressure of the gas on the shot can never exceed above a twentieth part of what it is in the 12-inch gun, and hence in the case of the rifle the pressure may gun, and hence in the case of the rill be insufficient to ignite the powder between the shot.

This view of the action resulting from the firing of powder by percussion appears to me to be one which it would be well worth while to test, for if proved it would completely re-establish confidence in the strength of the guns, which has been somewhat rudely shaken.

Let a 12-inch gun be loaded with a double charge of powder and a double charge of shot, or a shot of double veight, and fired. If, as is probable, the gun does not burst, confidence in the gun will be re-established. Then let it be loaded twice over with the powder between the shot so as to ascertain whether the action of the powder when fired by percussion would not produce an effect similar to that which we are here considering. The destruction of one gun for the purpose of establishing confidence in all the rest would not seem to be an unworthy sacrifice.

\section{MOSELEY'S NATURALIST ON THE "CHALLENGER"1}

THIS is certainly the most interesting and suggestive book, descriptive of a naturalist's travels, which has been published since Mr. Darwin's "Journal of Researches "appeared, more than forty years ago. That it is worthy to be placed alongside that delightful record of the impressions, speculations, and reflections of $\mathbf{a}$ master-mind, is, we do not doubt, the highest praise which Mr. Moseley would desire for his book, and we do not hesitate to say that such praise is its desert. The same argus-like power of observation, the same readiness to appreciate the true interest and significance of every seemingly little fact, the same energy and indomitable perseverance in gathering information and material from every source in the short space of time at the circumnavigator's disposal which distinguished $\mathrm{Mr}$. Darwin, characterise also his disciple and follower in many a distant ocean land and tropical forest.

Before the Challenger expedition set sail, Mr. Moseley was known as an accomplished biologist, trained in the laboratories of Stricker, of Vienna, and of Ludwig, of Leipzig. He had taken part in the eclipse expedition to Ceylon, and besides making valuable spectroscopic observations on the sun, had found time when there to stucy and collect specimens of the land Planarian Worms, the structure of which was the subject of a memoir by him in the Philosophical Transactions (published after the Challenger had left in 1874) which threw altogether new light on such important matters as the nature of metameric segmentation and the origin of the blood-lymph space, coelom, or body-cavity of higher organisms generally.

During the Challenger expedition, and since its return in I 876 (when he was by special statute elected to a "research" fellowship by the members of his old college of Exeter, in Oxford), Mr. Moseley has, apart from this volume and its varied contents, produced a series of original memoirs published chiefly by the learnet societies of London, which have been the means of making known the most important of the results to which the Challenger expedition has led in the field of biological science. It is to his industry and skill, combined with the opportunity afforded by the Challenger's cruise, that we owe the thorough description of the anatomy of the worm-like land-living Peripatus, and its development, studied by him at the Cape of Good Hope (Philosophical Transactions, 1874), whereby a totally new light is thrown upon the relationships of the great group of Hexapodous and Myriapodous insects, and the origin of tracheæ; to him we are indebted for the discovery and description of the most remarkable among the many pelagic or surface animals taken by the Challenger on the high seas, the transparent Pelagonemertes (Annals and Mag. Nat. Hist, 1875), as well as for the detection of the only really markedly aberrant form of life dredged by the Challenger in deep waters (Linnean Transactions, 1878 ), the Ascidian, Octacnemus bythius. The colouring matters, also, of various marine animals have been studied by him with the spectroscope and the spectra, carefully recorded in the Quart. Joum Microsc.Sci. I 877. But of still greater importance and merit was Mr. Moseley's study of corals allied to Millepora and $\therefore$ Notes by a Naturalist on the Challen ger. By H. N. Moseley, M.A. F.R.S., Fellow of Exeter Cullege, Oxford. 